\title{
FEM numerical analysis of the compaction of a mixture of brake pad components taking account of the real shapes and dimensions of particles
}

\author{
R. Moszumański ${ }^{1}$, T. Trzepieciński ${ }^{2} *$ \\ ${ }^{1}$ Faculty of Mechanical Engineering, Cracow University of Technology, Al. Jana Pawta II 37, 31-864 Kraków, Poland \\ ${ }^{2}$ Faculty of Mechanical Engineering and Aeronautics, Rzeszow University of Technology, \\ Al. Powstańców Warszawy 8, 35-959 Rzeszów, Poland
}

Received 30 April 2018, received in revised form 4 October 2018, accepted 5 October 2018

\begin{abstract}
The aim of this paper is the numerical prediction of the behaviour of the powder used during the compaction of the compound of which brake pads are composed. The numerical simulations using the finite element method were carried out in the MSC.Marc 2014 program for the case of the compaction of a representative model of compacted material. Due to the cylindrical shape of the compacted material and the randomly determined distribution of powder particles in the compound, the assumption was made that one could simulate the 2D model with appropriate boundary conditions. The shape and size of the compound particles were determined using an optical microscope. The properties of the particles were considered as elastic-plastic. It was found that particles of flake graphite, zinc oxide and synthetic graphite are subjected to the greatest plastic deformation. The smallest values of deformation occur during the compacting of particles undergoing the work hardening phenomenon, i.e. steel and brass wools. The phenomenon of strain hardening affects the nature of particle interactions (particle distribution) and the value of the maximum equivalent plastic strains obtained for individual strengthening models.
\end{abstract}

K e y words: brake pad, finite element method, powder compaction, numerical modelling

\section{Introduction}

Nowadays, one can observe the intensive development of manufacturing technologies which result from a high demand for innovative products with complex shapes. The sintered elements produced by powder metallurgy (PM) methods guarantee good resistance to friction wear, a low coefficient of friction and high heat resistance. Powder metallurgy is often the only way to obtain products with a specific chemical composition and properties.

Powder compaction (PC) is one of the main technological processes in the production of sintered metal products. Formation by compaction can be considered as densification of granulate, powder or other ceramic or metallic material by application of one-directional or multi-directional external forces in a rigid mould [1]. Compaction aims to form parts with specific di- mensions and shape, and appropriate density and specific physicochemical properties. PC is an economical method due to the high efficiency, small cost and relatively small amount of waste during the production process.

The PM process can produce complicated geometries that are difficult to produce by conventional machining approaches. This advantage reduces the setup time and manufacturing costs [2]. The PC process is carried out in rigid matrices. After having filled in a matrix, a weighed amount of powder is compacted by pressing the punch and then pushed out of the die. During compaction, the density of powder loosely poured into the matrix is reduced by two- or more times. The applied plastic deformation results in an increase in the contact area of powder particles. An increase of compacting pressures usually also leads to a decrease in the porosity of the bulk material $[3,4]$.

*Corresponding author: tel. +4817 8651714; e-mail address: tomtrz@prz.edu.pl 
According to Březina et al. [5], the porosity of the processed bulk material is usually considered to be a disadvantage of the powder metallurgy processing techniques [5]. The chemical composition, compressibility, microstructure, and size and shape of individual particles all play an important role in determining the bulk properties of the compacted powder, and furthermore, they influence the sintering process [6].

In the PM process, different methods are used to consolidate metal and ceramic powders into structural shapes. Uniaxial die pressing and cold isostatic pressing (CIP) are the two main methods in use [7]. The advantages of the uniaxial die pressing method include the possibility of pressing components that have a large geometrical shape, material and energy severity precision and a high rate of productivity [7]. With isostatic pressing, some of the constraints that limit the geometry of parts compacted unidirectionally in rigid dies are eliminated [8].

The powder compaction process can be numerically modelled using two main approaches [9-11]:

- continuum methods, where the powder is regarded as a mechanical continuum,

- discrete methods, where the behaviour and interaction of individual particles are considered.

Powders can also be regarded as granular and porous materials, the behaviour of which is similar to rocks and soils [12]. The numerical simulation of the PC process can predict the properties of the compacted element and estimation of forming forces [13]. An appropriate material model of the powder and appropriate boundary conditions are important for the predictive capability of the simulations [14]. The properties of the powder, i.e., apparent density, ability to flow, particle shape and particle size distribution, are necessary to ensure the correct physical description of the material in the numerical model [15].

The finite element method (FEM) is the main numerical method which provides a viable means of simulating the powder forming process. However, there are some difficulties in the numerical procedures due to the very nonlinear contact conditions and models which are necessary to describe the process. The finite element method has been widely used for simulating the compaction of metal powders [16]. To describe the compaction behaviour of the metal powder, classical elastic-plastic material models, expanded from the von Mises yield criterion with appropriate yield surfaces, were frequently employed (i.e., Kuhn and Downey [17], Green [18]). The powder aggregate can also be considered to be an elasto-plastic material with yield functions which were originally developed from soil mechanics [19]. The effect of adhesion between two idealplastic particles was included by Mesarovic and Johnson [20]. The adhesive effects and strain hardening of the powder particles with elastic-plastic behaviour were studied by Olsson and Larsson et al. [21] and Skrinjar et al. [22]. The yield criteria and flow rules for porous ductile media developed by Gurson [23] have been incorporated into the finite element (FE) code and used by Diarra et al. [24], Krok et al. [25], Mazor et al. [26] and Zhou et al. [27] to simulate granular materials. Some of the FEM codes allow one to simulate the behaviour of powders based on soil models, e.g. Drucker-Prager, modified Drucker-Prager, extended Cam-Clay, Mohr-Coulomb [28].

This paper presents the FEM numerical predictions of the behaviour of powder during compaction of the compound on a brake pad. The FEM elasticplastic numerical simulations were carried out in the MSC.Marc 2014 program for the case of compaction of a representative model of the compacted product. The shape and size of compound particles in the FE model corresponded to the real size found using digital image analysis of photographs of compound components under the microscope.

\section{Material}

The numerical simulations of powder compaction were carried out for a mixture containing components

Table 1 . The basic mechanical properties of the particle materials [29-35]

\begin{tabular}{lcccr}
\hline Material (denotation) & $\begin{array}{c}\text { Density } \rho, \\
\left(\mathrm{kg} \mathrm{m}^{-3}\right)\end{array}$ & $\begin{array}{c}\text { Young's modulus E, } \\
(\mathrm{GPa})\end{array}$ & $\begin{array}{c}\text { Yield stress } R_{\mathrm{e}}, \\
\text { Poisson's ratio } \nu \\
\text { compression strength } R_{\mathrm{c},} \\
(\mathrm{MPa})\left(^{*}\right)\end{array}$ \\
\hline Steel wool (A) & 7860 & 210 & 0.30 & 162 \\
Brass wool (B) & 8550 & 115 & 0.37 & 95 \\
Flake graphite (C) & 2150 & 795 & 0.27 & 60 \\
Synthetic graphite (D) & 2800 & 11 & 0.31 & 55 \\
Coke (E) & 2700 & 23.5 & 0.25 & 30 \\
Zinc oxide 99.5 (F) & 540 & 110 & 0.33 & 50 \\
Synthetic aluminium trioxide (G) & 3980 & 300 & 0.21 & 930 \\
\hline
\end{tabular}

${ }^{*} R_{\mathrm{p} 0.2}$ in the case of $\mathrm{A}-\mathrm{D}, \mathrm{F}$ materials; $R_{\mathrm{c}}$ in the case of $\mathrm{E}$ and $\mathrm{G}$ material 

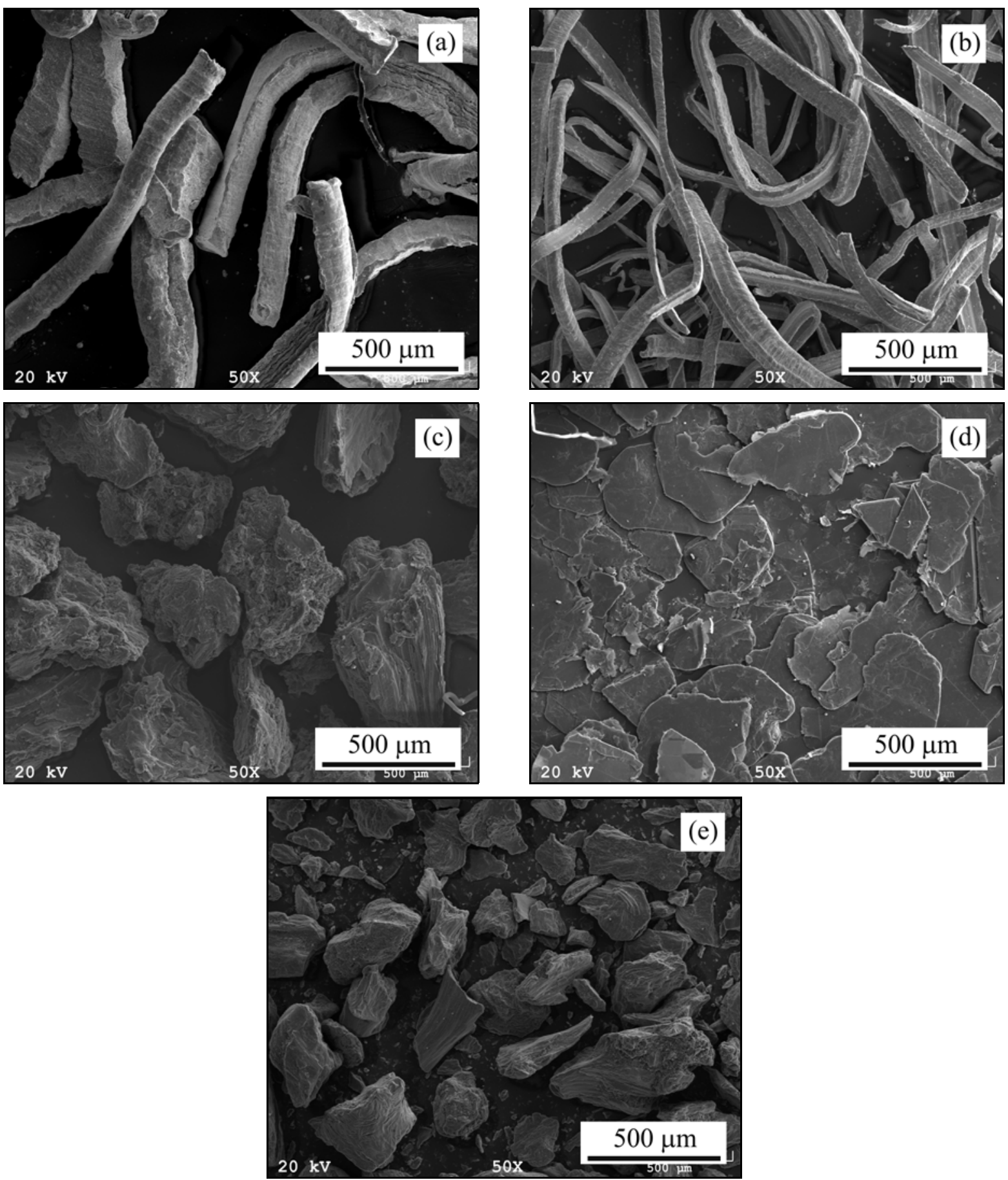

Fig. 1. Microphotographs of components of the mixture: (a) steel wool, (b) brass wool, (c) coke, (d) flake graphite, (e) synthetic graphite.

of the brake pad. The ratio between the filling height of the mixture and the height of the finished product is 2.4 to 1 , so the volume fraction of air in the powder mixture is about $58.3 \%$. The density of the mixture was $695 \mathrm{~kg} \mathrm{~m}^{-3}$. The basic mechanical properties of the powder components are presented in Table 1.

The flowability of the mixture and its susceptibility to compression depend on the shape of the particles. The shape and dimensions of individual parti- cles adopted for modelling in the numerical simulation were determined by digital image analysis of the microphotographs of components of the mixture (Fig. 1). Most of the materials included in the analysis do not show a regular shape. Therefore, the Hausner method was used to determine the shape of the particles in which two indicators were determined:

- the ratio of extreme dimensions $x=a / b$, where $a$ is length of the rectangle and $b$ is width of the rect- 
a

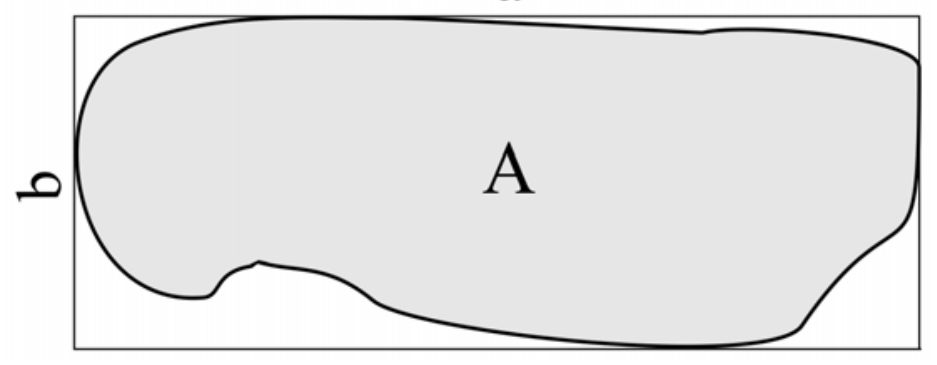

Fig. 2. A projection of the particle to determine particle shape using the Hausner method.

angle (Fig. 2),

- the degree of filling the rectangle with the particle $y=A /(a \times b)$, where $A$ is the area of the projection of the particle (Fig. 2).

Based on measurements of ten particles for each substance carried out in the AutoCAD program, the following shapes and dimensions were determined:

- steel wool: elongated, irregular shape and crosssectional area of approximately $450 \mathrm{\mu m}^{2}$,

- brass wool: the shape of the particles is elongated, with an irregular cross-section similar to a rectangle and a cross-sectional area of approx. $1000 \mu \mathrm{m}^{2}$,

- synthetic aluminium trioxide: regular (spherical) shape, about $3 \mu \mathrm{m}$ in diameter,

- flake graphite: flake shape with a diameter of approximately $80 \mu \mathrm{m}$ and a thickness of approx. $20 \mu \mathrm{m}$,

- synthetic graphite: irregular particle shape inscribed in a parallelepiped with dimensions of $80 \times 60$ $\times 60 \mu^{3}$,

- coke: irregular particle shape inscribed in a cube with $40 \mu \mathrm{m}$ side,

- zinc oxide 99.5: regular (spherical) shape, about $2 \mu \mathrm{m}$ in diameter.

\section{Numerical modelling}

The precondition for starting MES calculations is to perform detailed numerical models of the problem analysed and then to simplify them and discretise them in a selected calculation program to obtain an equivalent model to the mathematical model of a continuous body. Simplifying the model involves removing unnecessary details from the geometry of the particles, such as pores and small rounding of edges, which do not significantly affect the accuracy of the solution. It significantly accelerates the processing of the model. The discretisation of the model consisted of the division of particles into a finite number of elements with a specific shape.

The geometry of the compaction process was modelled in the FEM-based MSC.Marc program. In the cross-section considered, 13000 particles were generated in accordance with the particle dimensions, which were discretised with 11,575,000 4-node elements (Fig. 3). Due to the technical difficulties involved in computing a model with such a large number of nodes, it was decided to simplify the model at a 1/2500 scale (Fig. 4) with 4630 elements. Particles of the mixture are not in physical contact because the model presented is a random cross-sectional view (see example in Fig. 5), maintaining porosity of $58.3 \%$. The surfaces of punch and form were considered as rigid.

The mechanical properties of the simulated materials were treated as elastic-plastic, with the properties given in Table 1. The isotropic material behaviour described by Huber-Mises-Hencky (H-M-H) yield criterion is considered. For the ideal case of isotropic mate-

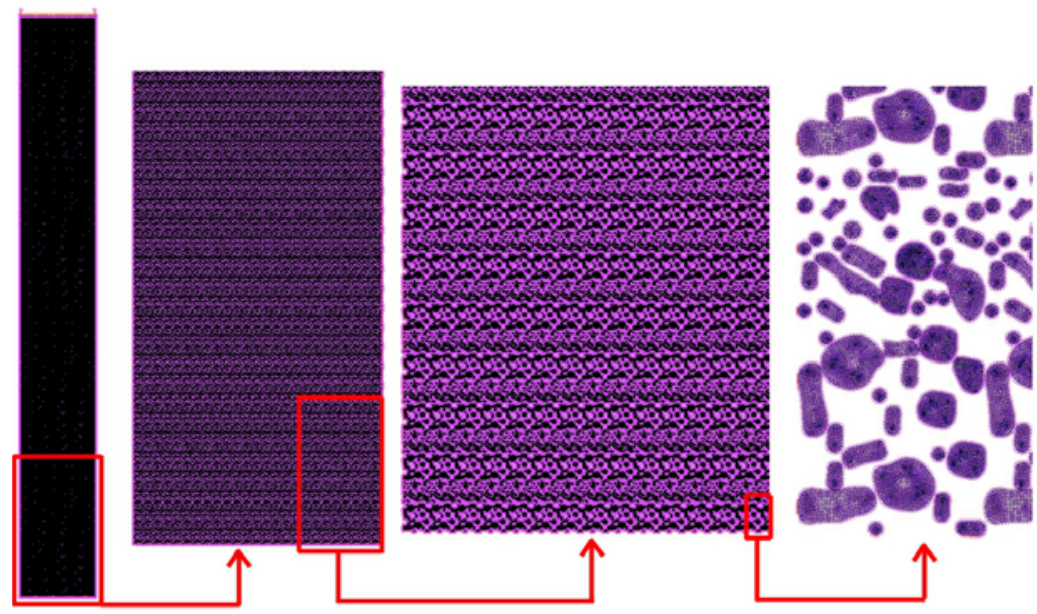

Fig. 3. Mesh of finite elements of the problem of the compaction of a mixture forming a brake pad which was considered in the study. 


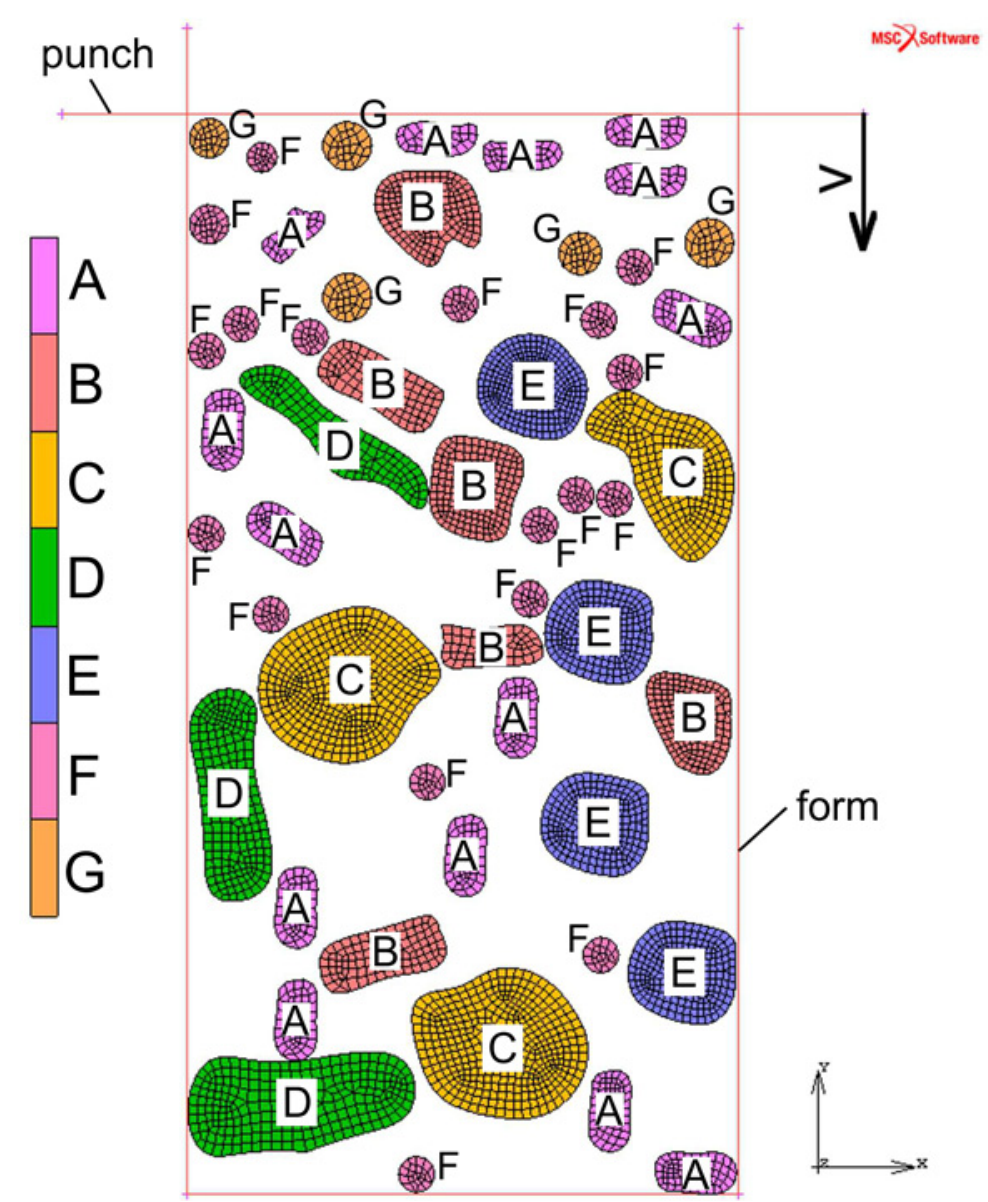

Fig. 4. Model of the mixture subjected to compression in the FEM simulation, the dimensions of the model of the loading chamber $0.22 \times 0.432 \mathrm{~mm}^{2}$.

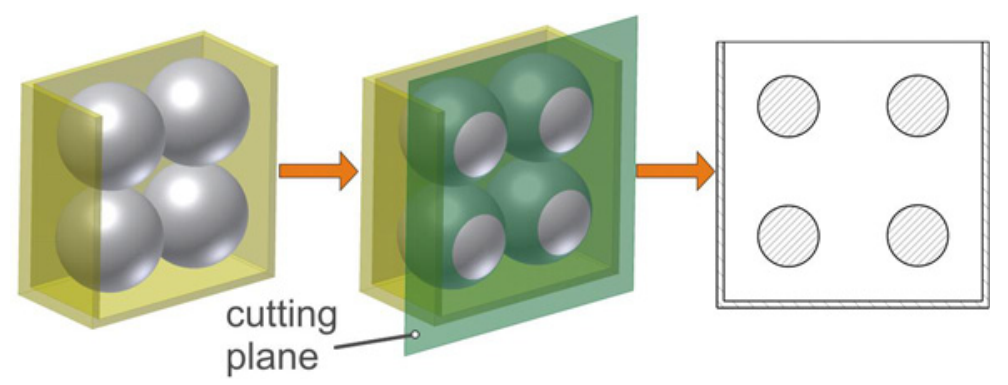

Fig. 5. The methodology of model creation.

rials, H-M-H yield condition is expressed as:

$$
\bar{\sigma}^{2}=\frac{\sqrt{2}}{2} \sqrt{\left(\sigma_{1}-\sigma_{2}\right)^{2}+\left(\sigma_{2}-\sigma_{3}\right)^{2}+\left(\sigma_{3}-\sigma_{1}\right)^{2}}
$$

where $\bar{\sigma}$ is the equivalent $\mathrm{H}-\mathrm{M}-\mathrm{H}$ stress and $\sigma_{1}-\sigma_{3}$ are the principal stresses.

Furthermore, material models of steel wool and brass wool took into account the non-linear work hardening phenomenon. To describe hardening properties of the steel and brass material the Hollomon equation
[29] was used:

$$
\sigma=K \varepsilon^{n}
$$

where $\sigma$ is the true stress and $\varepsilon$ is the true strain. The values of the parameters $K$ and $n$ in Hollomon equation were determined from the logarithmic true stress-true strain plot by linear regression. The mean value of $n$ exponent for the whole range of strain is usually assumed in numerical simulations. Figure 6 shows the strain hardening curves plotted based on the values of the hardening parameters listed in Table 2 .

The friction contact between the powder particles 


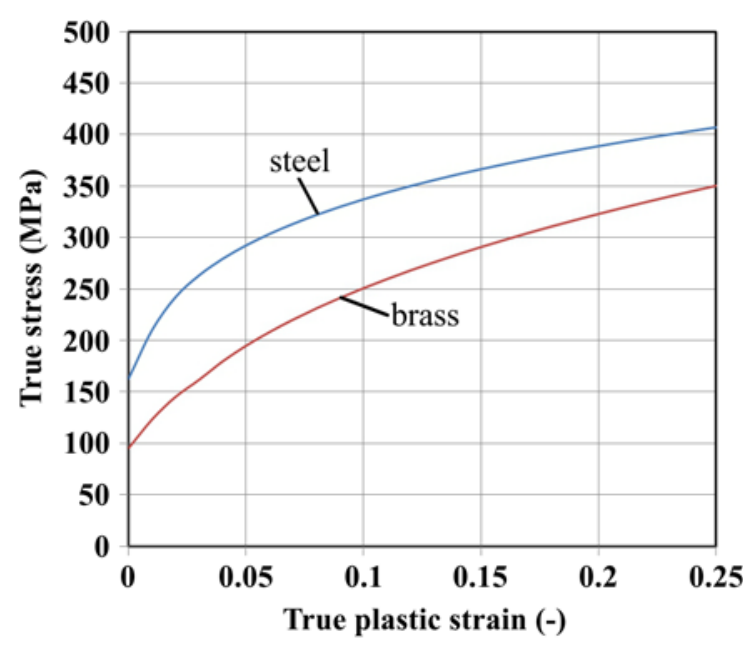

Fig. 6. Strain hardening curves of steel and brass. was taken into account according to the Coulomb law. It was assumed that the coefficient of friction is equal to $\mu=0.2$. The value of friction coefficient between the particles is much higher than the friction coefficient between the particles and surfaces both of form and punch [40]. So, the friction coefficient between the particles and the tool surfaces was assumed to be $\mu=$ 0.05. When the punch starts to move down the particles are moved with him from top to bottom. If no contact is detected between the separate particles, they do not move.

The simulations of powder compaction were carried out under static and dynamic conditions, with speeds of 10,20 and $30 \mathrm{~mm} \mathrm{~s}^{-1}$. In the static conditions, the speed was equal to $1 \mathrm{~mm} \mathrm{~s}^{-1}$. The initial configuration of the particles in the FEM models analysed is shown in Fig. 4.

Ta ble 2. The values of parameters in the Hollomon equation

\begin{tabular}{lcc}
\hline Material & Hardening coefficient $K(\mathrm{MPa})$ & Hardening exponent $n$ \\
\hline Steel & 542 & 0.206 \\
Brass & 581 & 0.365 \\
\hline
\end{tabular}

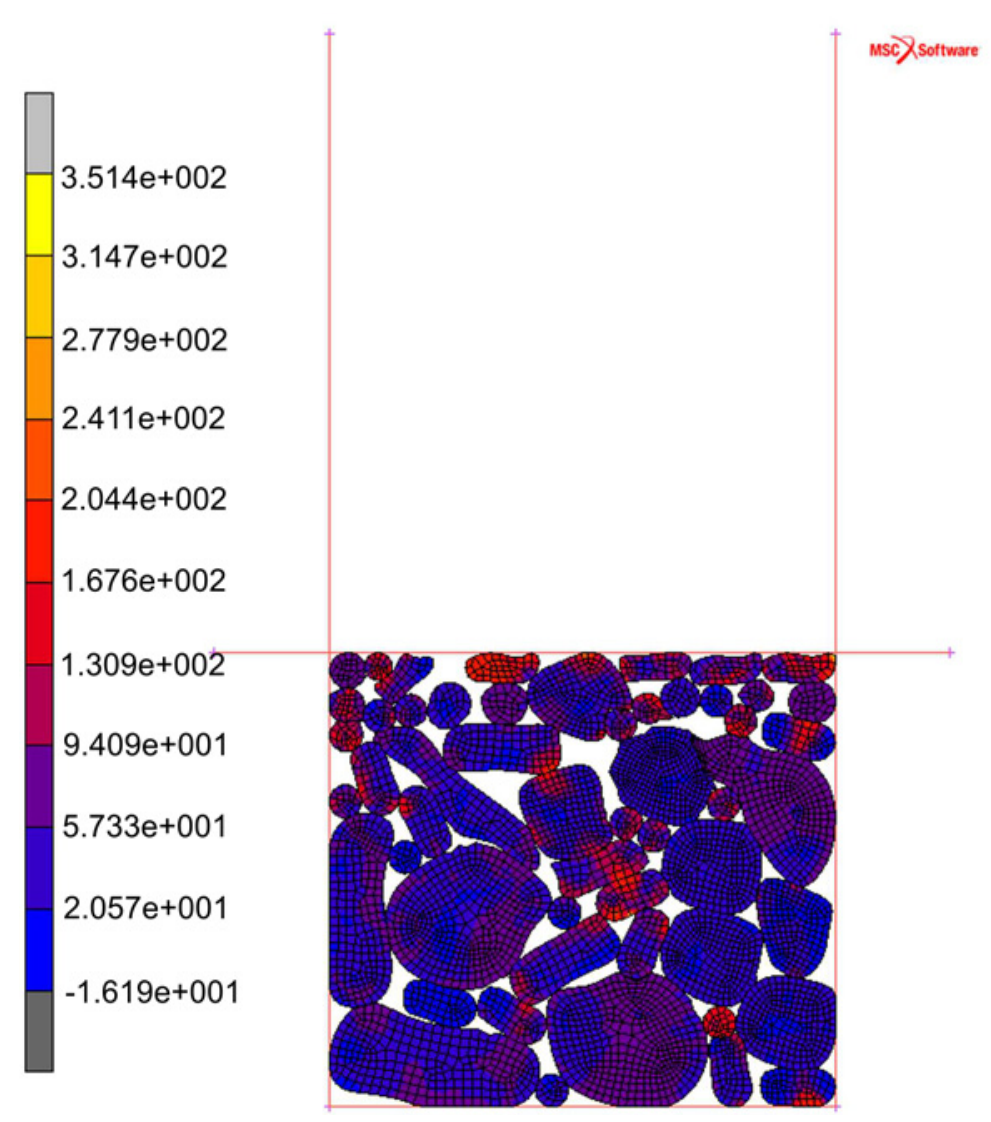

Fig. 7. The distribution of equivalent Huber-Mises-Hencky stress (MPa) in compacted powder. 


\section{Results and discussion}

Steel and brass are materials that are characterised by work strengthening during the plastic deformation process. The change of mechanical properties along with the increase of deformation affects the value of the compaction force and whether it is possible to compact the mixture of particles of the brake pad.

During powder compaction, the following phenomena occur:

- making the grains of the powder approach sufficiently close to allow adhesion,

- enlarging the contact surface between powder grains by bringing them closer together,

- enlargement of the degree of contact between particles by plastic deformation,

- removal of oxide films by mutual friction between neighbouring grains.

In the final stage of the compaction process, there is a rearrangement of particles by slipping disordered particles and the plastic interaction of the softest components (Fig. 7). At this stage, a significant increase in the value of the compaction force leads to a slight increase in the compaction of the mixture. When selecting the particle size of a mixture fraction, it is important to remember that the particle size of each finer fraction should be smaller than the free space between the particles of the thicker fraction. The physicochemical properties of the brake pad depend not only on the type of ingredients used but also on their granularity and the accuracy of mixing the components.

The highest stress values were observed during the interaction of the particles of steel wool with brass wool and synthetic aluminium oxide, which exhibit a high value of compression strength. The properties of the rest particles are considered as non-workhardenable. So, they do not exhibit high stresses. Maximum values of H-M-H stress shown in Figs. 7 and 8 are a result of local stress concentration observed in the place of interaction of two or a few particles.

No significant displacements of the material particles within the pressed mixture were observed during the compaction. It was found that flake graphite, zinc oxide and synthetic graphite are subject to the greatest plastic deformation. The smallest values of deformation occur during the pressing of particles undergoing work strengthening, i.e. steel wool and brass wool.

Cracking may occur during the compaction of fine particles due to stresses caused by the presence of air pores in the compacted structure. A small pore volume is a barrier to evacuating the gas phase and leads to an increase in the internal stresses in the compacted product. Facilitating the evacuation of air can be achieved by using fractions composed of large particles while minimising the volume of fine particle fractions. Particles with a very high degree of disintegration can
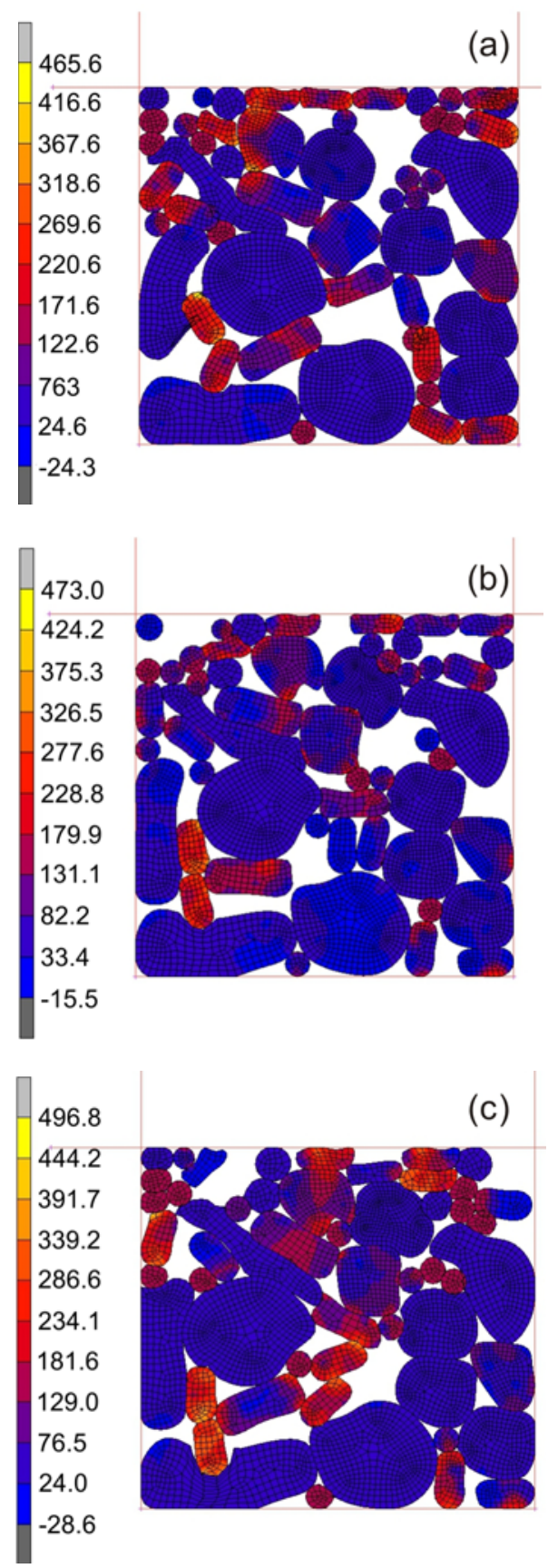

Fig. 8. The distribution of equivalent Huber-Mises-Hencky stress $(\mathrm{MPa})$ in a powder compacted at a speed of (a) $10 \mathrm{~mm} \mathrm{~s}^{-1}$, (b) $20 \mathrm{~mm} \mathrm{~s}^{-1}$, and (c) $30 \mathrm{~mm} \mathrm{~s}^{-1}$.

be subjected to the agglomeration process, which produces so-called granules with the required size, shape and density.

With an increase in compaction speed in the range of $10-30 \mathrm{~mm} \mathrm{~s}^{-1}$, there is an increase in the maximum value of equivalent stress. Changing the speed of movement of the punch also leads to a different arrangement of particles in the mould (Fig. 8).

The highest value of equivalent plastic strains was 


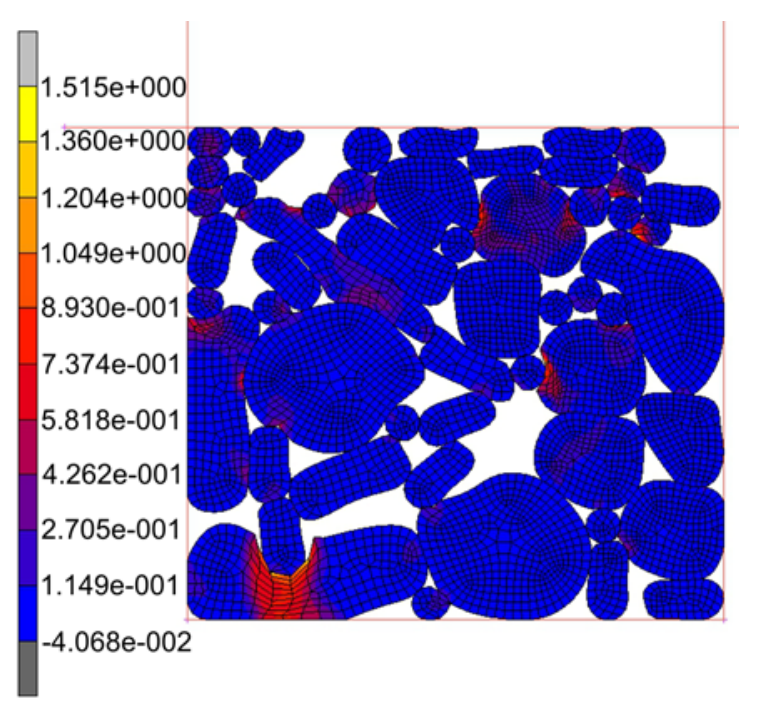

Fig. 9. The distribution of equivalent plastic strains in a powder compacted at a speed of $30 \mathrm{~mm} \mathrm{~s}^{-1}$.

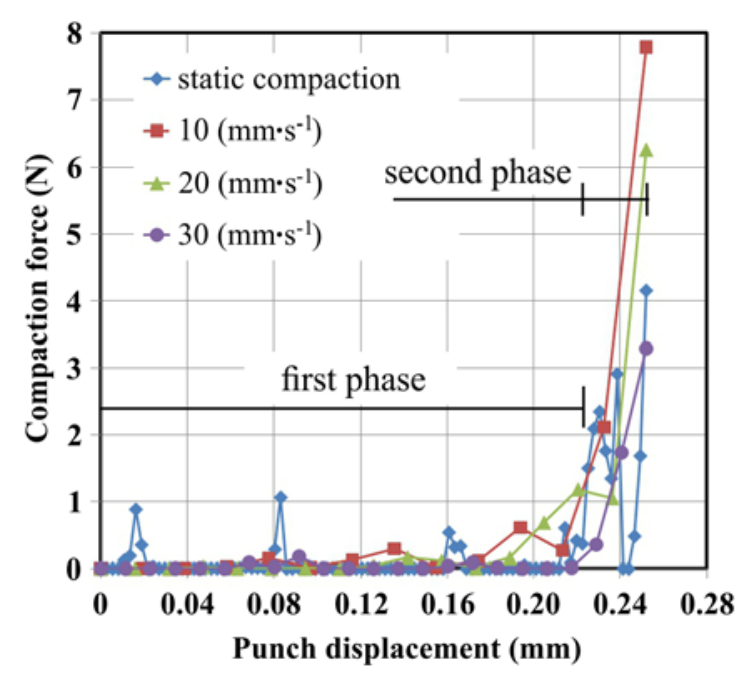

Fig. 10. Comparison of the compaction force for static and dynamic processes.

observed for a compaction speed of $10 \mathrm{~mm} \mathrm{~s}^{-1}$. Increasing the speed of deformation causes the value of maximum strains to be reduced. In all cases, the most distorted particles are coke and synthetic graphite. The simulations did not take into account the criterion of material destruction but based on the interaction of the steel wool particle and the synthetic graphite particle shown in Fig. 9, the graphite may crack. In some cases of FEM analysis of the compaction of powders, the interaction of particles with the highest strength may result in a local accumulation of strains.

The highest value of the compaction force was recorded for compaction at a speed of $10 \mathrm{~mm} \mathrm{~s}^{-1}$. This value is more than $180 \%$ of the force necessary to

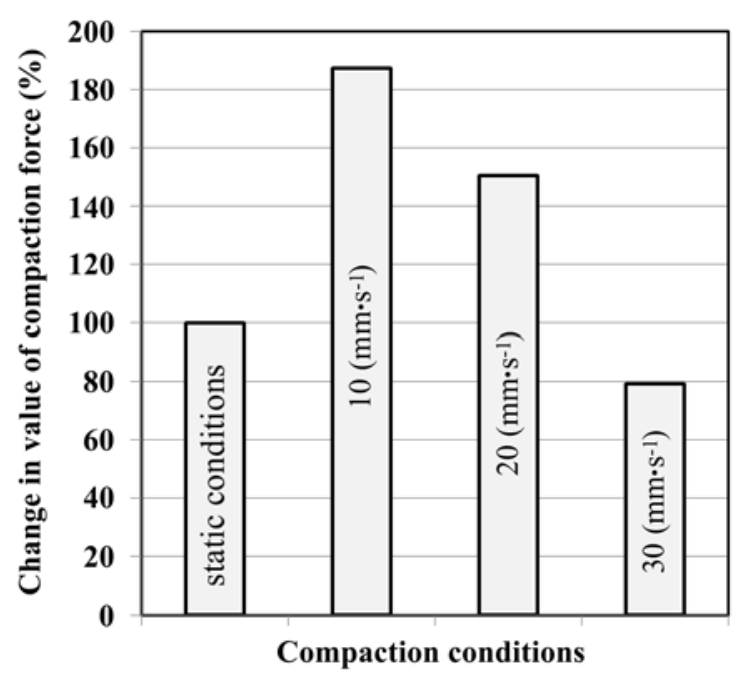

Fig. 11. The change in the value of the compaction force for a dynamic process in comparison with static conditions.

compact the particles under static conditions. The values of the numerically predicted compaction forces for a representative model of compacted material, shown in Fig. 10, cannot be simply compared with the values of the real compaction force. The model analysed is a fragment of the $2 \mathrm{D}$ compression model (Fig. 3), where there is a stochastic distribution of particles, so the values of forces obtained cannot be proportionally related to the real compression force. However, it is possible to qualitatively analyse the effect of the speed of the punch on the change in the value of the compaction force (Fig. 11) registered at the final stage of the process. In the case of dynamic compaction, the compaction force decreases with an increase in punch movement speed in the range of 10$30 \mathrm{~mm} \mathrm{~s}^{-1}$. The most favourable value of compaction force was recorded for a punch moving speed equal to $30 \mathrm{~mm} \mathrm{~s}^{-1}$.

During the first phase of the compaction process (Fig. 10) small values of the compaction force occur compared to those in the final stage of forming. In this phase, the particles move as a result of the interaction with the surface of the punch, increasing the degree of matching to each other. The elimination of possible bridges also occurs in the mixture structure. The frictional nature of the contact between the particles can cause the removal of oxide layers from the surface of the particles. In the second phase (Fig. 10), a rapid increase in the strength of the particle occurs as it undergoes the strain hardening phenomenon; the particles with low compressive strength crack, thus creating the possibility of better filling of the mould.

As mentioned above, the steel and brass wool material subjected to plastic deformation as a result of interaction with other particles in the mixture is particularly susceptible to strain strengthening. From 
Ta ble 3. Multipliers $\lambda$ for modifying the yield stress both of steel and brass wool

\begin{tabular}{lccccc}
\hline & \multicolumn{5}{c}{ Work hardening models } \\
\cline { 2 - 6 } Material & I & II & III & IV & V \\
\hline Steel & $\times 1$ & $\times 0.5$ & $\times 0.5$ & $\times 1$ & $\times 1.5$ \\
Brass & $\times 1$ & $\times 0.5$ & $\times 1$ & $\times 0.5$ & $\times 1.5$ \\
\hline
\end{tabular}

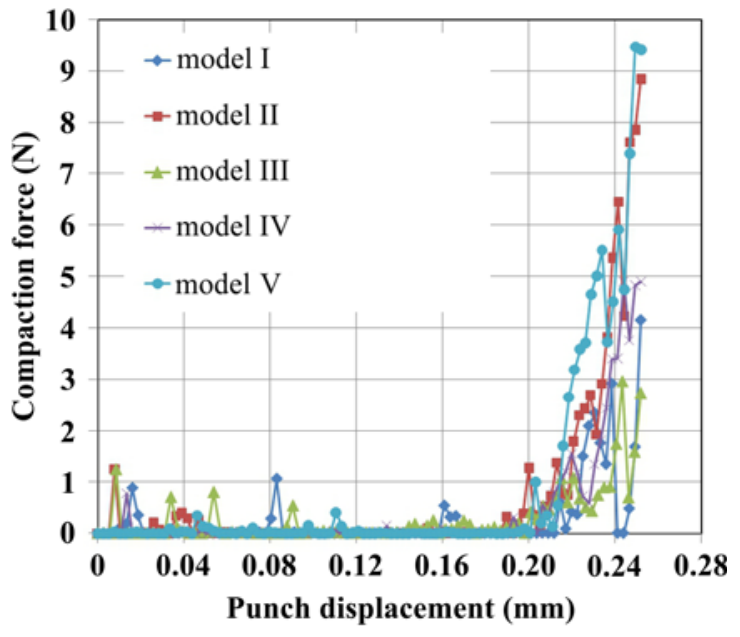

Fig. 12. Comparison of the compaction force for the hardening models analysed.

the point of view of the mechanical strength of the compacted product, it is advantageous to use wool from materials with a high tendency to deform. On the other hand, the use of materials with a low tendency to strengthening enables a higher concentration of wool particles in the structure of the brake pad. There is no unequivocal certainty about the influence of work hardening on the course of the technological process and the value of the compaction force, and this requires additional analyses.

Four strengthening models of steel and brass wool materials are considered in the numerical simulations. These models are created based on a modification of the real hardening curves (Fig. 6) by the use of multipliers $\lambda$ (Table 3 ) which increase and decrease the real values of yield stresses, according to the modification of Eq. (2):

$$
\sigma=\lambda K \varepsilon^{n}
$$

The values of multipliers $\lambda$ listed in Table 3 were assumed to study the effect of plastic properties of steel and brass on the compaction force.

The largest compression force for the model was recorded (model $\mathrm{V}$ in Fig. 12) by taking into account the increase in the yield stress of the steel and brass wool particles by $50 \%$. The value of the compaction force for model II, which takes into account a $50 \%$

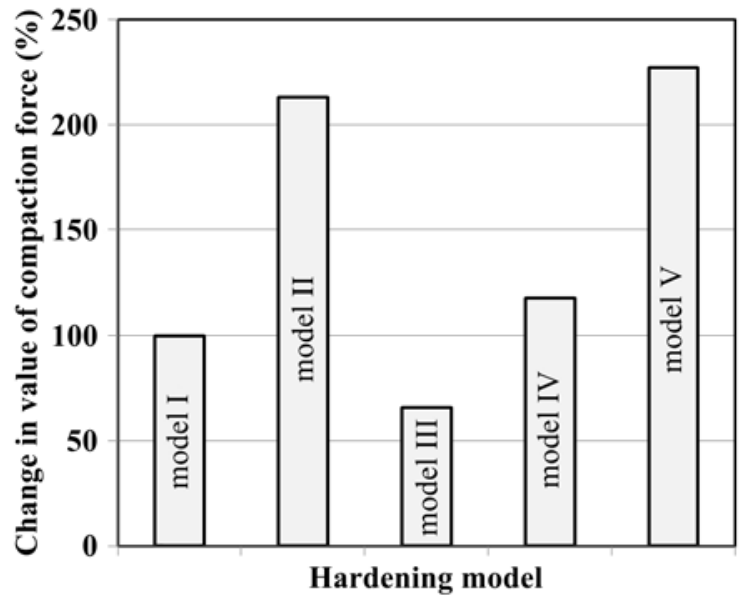

Fig. 13. The change in the value of the compaction force for the hardening models analysed in relation to the real hardening of steel and brass.

reduction in the yield stress of the wool materials, is similar to the $\mathrm{V}$ model. This result may be surprising. However, attention should be paid to an increase in the contact surface of materials with reduced plasticity (model II), which translates into a high value of the compaction force. The qualitative analysis of the compaction force for different strengthening models (Fig. 13) showed that steel wool with reduced work hardening properties should be used to reduce the value of the compaction force.

\section{Summary and conclusions}

The FEM-based numerical investigations undertaken were focused on the study of the compaction process of the mixture used in the fabrication of brake pads, including consideration of the real shape and real dimensions of the mixture of compounds. The numerical results allow the following conclusions to be drawn:

- the smallest values of deformation occur during the compacting of particles undergoing the work hardening phenomenon, i.e. steel and brass wools,

- the phenomenon of work hardening affects the nature of particle interactions and the value of maximum equivalent plastic strains obtained for all strengthening models analysed, 
- the use of wool from materials with a high tendency to deformation could increase the mechanical strength of the compacted product, due to the better filling of the pores in the compacted product (better densification),

- with an increase in compaction speed in the range of $10-30 \mathrm{~mm} \mathrm{~s}^{-1}$, there is an increase in the maximum value of equivalent stress,

- the highest value of compaction force was recorded for compaction at a speed of $10 \mathrm{~mm} \mathrm{~s}^{-1}$; however, the lowest value of compaction force is observed with the highest punch movement speed considered, i.e. $30 \mathrm{~mm} \mathrm{~s}^{-1}$.

\section{References}

[1] Aydin, I., Briscoe, B. J., Ozkan, N.: MRS Bulletin, 22, 1997, p. 45. doi:10.1557/S0883769400034746

[2] Verma, R. K., Mahesh, N. S., Anwar, M. I.: SASTECH, 11, 2012, p. 79.

[3] Kayhan, S. M., Tahmasebifar, A., Koç, M., Usta, Y., Tezcaner, A., Evis, Z.: Mater. Des., 93, 2016, p. 397. doi:10.1016/j.matdes.2015.12.177

[4] Meng, F., Rosalie, J. M., Singh, A., Tsuchiya, K.: Mater. Sci. Eng. A, 644, 2015, p. 386. doi:10.1016/j.msea.2015.07.086

[5] Březina, M., Minda, J., Doležal, P., Krystýnová, M., Fintová, S., Zapletal, J., Wasserbauer, J., Ptáček, P.: Metals, 7, 2017, p. 1. doi:10.3390/met7110461

[6] Yavuz, N.: J. Eng. Sci., 2, 1996, p. 129.

[7] Eksi, A., Kulekci, K.: Metalurgija, 43, 2004, p. 129.

[8] Wheeler, F. S.: Ceram. Eng. Proc., 7, 1986, p. 1242.

[9] Sinka, I. C.: Powder and Particle Journal, 25, 2007, p. 4. doi:10.14356/kona.2007005

[10] Garner, S., Strong, J., Zavaliangos, A.: Powder Technol., 330, 2018, p. 357. doi:10.1016/j.powtec.2018.02.015

[11] Jerier, J. F., Hathong, B., Richefeu, V., Chareyre, B., Imbault, D., Donze, F.V., Doremus, P.: Powder Technol., 208, 2011, p. 537. doi:10.1016/j.powtec.2010.08.056

[12] Sinka, I. C., Cocks, A. C. F., Pan, J.: Proceedings of the 2009 Simulia Customer Conference. London, DS SIMULIA 2009, p. 871.

[13] Svoboda, A.: Computational Modelling of Hot Isostatic Pressing. [PhD. Thesis]. Lulel', Lulel' University of Technology 1997.

[14] Häggblad, H. A., Oldenburg, M.: Model. Simul. Mater. Sci. Eng., 2, 1994, p. 893. doi:10.1088/0965-0393/2/4/006
[15] Olsson, E., Larsson, P. L.: Powder Technol., 243, 2013, p. 71. doi:10.1016/i.powtec.2013.03.040

[16] Chandler, H. W., Sands, C. M., Song, J. H., Withers, P. J., McDonald, S. A.: Int. J. Solids Struct., 45, 2008, p. 2056. doi:10.1016/j.ijsolstr.2007.11.021

[17] Kuhn, H. A., Downey, C. L.: Int. J. Powder Metall., 7, 1971, p. 15.

[18] Green, R. J.: Int. J. Mech. Sci., 14, 1972, p. 215.

[19] DiMaggio, F. L., Sandler, I. S.: ASCE J. Eng. Mech., 97, 1971, p. 935.

[20] Mesarovic, S. D., Johnson, K. L.: J. Mech. Phys. Solids, 48, 2000, p. 2009. doi:10.1016/S0022-5096(00)00004-1

[21] Olsson, E., Larsson, P. L.: J. Mech. Phys. Solids, 61, 2013, p. 1185. doi:10.1016/j.jmps.2013.01.004

[22] Skrinjar, O., Larsson, P. L., Storåkers, B.: J. Appl. Mech., 74, 2007, p. 164. doi:10.1115/1.2165240

[23] Gurson, A. L.: J. Eng. Mater. Tech. - Trans. ASME, 99, 1977, p. 2. doi:10.1115/1.3443401

[24] Diarra, H., Mazel, V., Boillon, A., Rehault, L., Busignies, V., Bureau, S., Tchoreloff, P.: Powder. Technol., 224, 2012, p. 233. doi:10.1016/j.powtec.2012.02.058

[25] Krok, A., García-Triñanes, P., Peciar, M., Wu, C. H.: Chem. Eng. Res. Des., 110, 2016, p. 141. doi:10.1016/j.cherd.2016.03.019

[26] Mazor, A., Perez-Gandarillas, L., de Ryck, A., Michrafy, A.: Powder Technol., 289, 2016, p. 21. doi:10.1016/i.powtec.2015.11.039

[27] Zhou, M., Huang, S., Hu, J., Lei, Y., Zou, F., Yan, S., Yang, M.: Powder Technol., 313, 2017, p. 68. doi:10.1016/j.powtec.2017.03.015

[28] Abaqus Theory Manual. Providence, Dassault Systèmes 2011.

[29] Nosal, S., Orłowski, T.: Tribologia, 5, 2010, p. 85 (in Polish).

[30] http://www.anser.pl/pub/Archiwalne_Karty_Charak terystyk/Biel\%20cynkowa\%20Kchsn\%2001.12.2010. pdf

[31] Technical data of Luvata Sweden AB, Poco Graphite Inc., Accuratus Corporation, Centrostal S. A.

[32] Tsai, J. L., Tu, J. F.: Mater. Des., 31, 2010, p. 194. doi:10.1016/j.matdes.2009.06.032

[33] Klose, W., Suginobe, H.: Steel Res. Int., 57, 1986, p. 250. doi:10.1002/srin.198600762

[34] Dornfeld, D., Lee, D. E.: Precision Manufacturing. New York, Springer 2008.

[35] Kudo, S., Mori, A., Hayashi, G., Yoshida, T., Okuyama, N., Norinaga, K., Hayashi, J. I.: Energy Fuels, 32, 2018, p. 4364. doi:10.1021/acs.energyfuels.7b03155

[36] Hollomon, J. H.: Trans. Amer. Inst. Mech. Eng., 162, 1945, p. 268.

[37] http://www.kmimp.agh.edu.pl/pliki/cz3.pdf (access 05.04.2018) 